\title{
Effect of Mycobacterium bovis infection in cattle on changes in appetite-related hormones
}

\author{
Şinasi Așkara ${ }^{a^{*}}$, Tünay Kontaş Așkara ${ }^{\mathrm{a}}$ Murat Güzel ${ }^{\mathrm{b}}$
}

\begin{abstract}
There are limited studies available for appetite-related hormonal changes in bovine tuberculosis, therefore the purpose of this study was to determine the changes in appetite-related hormones (leptin, ghrelin, and nesfatin -1) of cattle with tuberculosis and to clarify their possible roles. A total of 30 cattle, comprising 15 clinically healthy cattle and 15 cattle infected with tuberculosis were enrolled in the study. The diagnosis of tuberculosis was performed by tuberculin skin test, and changes in the concentrations of ghrelin, leptin, nesfatin-1, lipid profile and muscular enzymes in cattle with tuberculosis were determined. It was found that nesfatin-1, ghrelin and muscular enzymes concentrations were higher in bovine infected with tuberculosis than in the healthy controls. On the other hand, leptin, triglyceride, low density lipoprotein (LDL), high density lipoprotein (HDL), and total cholesterol levels were all lower in the tuberculosis group when compared to the control group. In this study, we detected serum nesfatin- 1 concentrations for the first time in Mycobacterium bovis infection in addition to the other known appetite-related hormones. The data suggest that increased concentrations of nesfatin-1 may play a role in weight loss in bovine tuberculosis, but there is a need for further studies to determine its exact role in the etiopathogenesis of bovine tuberculosis.
\end{abstract}

Key words: bovine tuberculosis, ghrelin, leptin, nesfatin-1.

\section{INTRODUCTION}

Bovine tuberculosis (BTB, Mycobacterium bovis infection), caused by Mycobacterium bovis, is a chronic infectious disease that affects humans and domestic animals, particularly cattle (Carstensen and DonCarlos 2011, Wang et al 2011). Among domestic animals, cattle are the primary reservoir for human tuberculosis, caused by M. bovis (Okafor et al 2011). Weight loss, cachexia and protein energy malnutrition are common signs of Mycobacterium bovis infection.

Nutrition is the most important factor affecting susceptibility to any infection. The association between TB and weight loss is well recognised (Şengül et al 2014). Serum feed regulating peptides like leptin and ghrelin are being cited causing weight loss in TB. Leptin is a protein hormone made up of 167 amino acids. Its main effect which relates to energy exhaustion and control of food intake is implicated as an anorexigenic factor that reduces appetite (Kim et al 2010, Yurt et al 2013). In addition, the adipocyte-derived hormone leptin has been shown to regulate the innate and adaptive immune response, both in normal and pathological conditions (Yurt et al 2013).

Conversely, ghrelin is a 28 -amino-acid peptide, which has been identified as the only known orexigenic hormone. It is produced by the stomach and plays a role in regulating

Accepted: 18.06.2018.

aDepartment of Nutrition and Dietetic, Faculty of Health Sciences, Çankırı Karatekin University, Çankırı, Turkey.

${ }^{\mathrm{b}}$ Department of Internal Medicine, Faculty of Veterinary Medicine, Ondokuz Mayıs University, Samsun, Turkey.

*Corresponding author: Ş Aşkar; sinasia@gmail.com pre-meal hunger and meal initiation as well as long-term energy balance. Ghrelin level increases in anorexic conditions and stimulates appetite (Ozturk et al 2013, Yurt et al 2013). Recently, leptin and ghrelin concentrations were shown to be changed in humans infected with tuberculosis (Kim et al 2010, Yurt et al 2013).

Another appetite-related hormone, nesfatin-1, may be a new potential cause of Mycobacterium bovis infection associated weight loss. Nesfatin-1, a recently discovered satiety peptide, contains 82 amino acids and is derived from NEFA/nucleobindin-2 (NUCB2). It was believed to be extensively responsible for the provision of appetite and metabolic regulation in the hypothalamus (Anwar et al 2014, Sengül et al 2014). This unique neuroendocrine peptide is measurable in the plasma, and becomes altered under different conditions in human. It is also involved in regulation of homeostasis via its important regulating role in food intake, appetite and body weight. It is identified as a satiety molecule that is associated with melanocortin signaling in the hypothalamus, decreasing food intake in a dose-dependent manner (Anwar et al 2014). Also, nesfatin-1 has anti-inflammatory and anti-apoptotic effects, and inhibits smooth muscle relaxation in vessels (Şengül et al 2014).

There are several reports on the status of appetite-related hormones in human tuberculosis (Keicho et al 2012, Kim et al 2010). However, there are limited studies available for the status of the appetite-related hormones in Mycobacterium bovis infection and there is no information about nesfatin-1 status in bovine or human tuberculosis. Therefore the purpose of this study was to determine the changes in the status of appetite-related hormones leptin, ghrelin, and nesfatin -1 and to clarify their possible roles on lipid and muscle metabolism in Mycobacterium bovis infection. 


\section{MATERIAL AND METHODS}

\section{ANIMALS AND SAMPLING}

A total of 30 cattle, comprising 15 clinically healthy control animals and 15 cattle with tuberculosis from the Samsun province of Turkey were enrolled on this study. The Samsun province is in northern Turkey on the Black Sea coast. Blood samples were collected in lithium heparin and silicon gel coated test tubes. Serum samples were separated by centrifugation at $2500 \mathrm{rpm}$ for $10 \mathrm{~min}$ at room temperature and kept at $-80^{\circ} \mathrm{C}$ until processing.

The clinical status of each cattle was carefully evaluated and those with two or more obvious clinical signs of tuberculosis such as enlarged lymph nodes, appetite loss, fever, conjunctivitis, dermatitis, mouth and skin ulcers besides weakness were regarded as infected with tuberculosis. Cattle without any of these signs were classified as asymptomatic (table 1).

The diagnosis of tuberculosis was detected by using the tuberculin skin test (TST). The TST was performed according to Bovine Tuberculosis Directive of Turkey Food and Agriculture Ministry. After clipping the bristle at the injection site, normal skin thickness was measured with a caliper and the injection site was disinfected. Cattle were inoculated with $0.1 \mathrm{~mL}$ of bovine PPD on the left side of the neck, and test results were determined by measuring the increase of the skin-fold thickness $72 \mathrm{~h}$ later. TST results were considered positive when there was an increase of $4 \mathrm{~mm}$ or more at the injection site.

\section{BIOCHEMICAL ANALYSIS}

Ghrelin, leptin, nesfatin-1, total cholesterol, HDL, LDL, and very high-density lipoprotein (VLDL) levels were determined in the blood samples. Serum triglycerides, total cholesterol, HDL levels, and the enzyme activities (aspartate aminotransferase-AST, alanine aminotransferase ALT, creatine kinase-CK) were analysed with the Roche Modular System autoanalyzer with enzymatic colorimetric method, by using Roche Diagnostic's reagent. Serum

Table 1. Clinical signs of tuberculosis in BTB group.

\begin{tabular}{lcc}
\hline Signs & $\mathrm{n}$ & $\begin{array}{c}\text { Percentage } \\
(\%)\end{array}$ \\
\hline Enlarged lymph nodes & 10 & 67 \\
Weakness & 12 & 80 \\
Fever & 6 & 40 \\
Pain & 3 & 20 \\
Dermatitis & 6 & 40 \\
Mouth and skin ulcers & 5 & 33 \\
Conjunctivitis & 6 & 40 \\
Apetite loss & 9 & 60 \\
\hline
\end{tabular}

VLDL and LDL levels were calculated with Friedewald formüle (Friedewald et al 1972, Osorio et al 2012, Kessler et al 2014) as follows:

$$
\begin{aligned}
\mathrm{VLDL}= & \text { Triglycerides } / 5 \mathrm{LDL}=\text { Total Cholesterol } \\
& -[(\mathrm{HDL})+(\text { Triglycerides } / 5)]
\end{aligned}
$$

Serum ghrelin levels were analysed by using commercial ELISA test kits according to the instructions of the manufacturer (Phoenix-EK, 031/30). The lowest measured concentration of ghrelin was $10 \mathrm{pg} / \mathrm{mL}$, with intra- and inter-assay $\mathrm{CV}$ values $<10 \%$ and $<15 \%$ respectively. All samples were run in duplicately in the assay. Leptin DRG ELISA kit (DRG-EIA, 2395) was used in the measurement of serum leptin levels. The lowest measured concentration of leptin was $2 \mathrm{ng} / \mathrm{mL}$, with intra- and inter-assay CV values of $8.1 \%$ and $9.6 \%$, respectively. All samples were run in duplicate in the assay.

Serum nesfatin-1 levels were measured by using a commercially available kit (Phoenix Pharmaceuticals Inc. USA). The procedures for determining the hormone levels were performed as recommended in the relevant catalogues, using microplayte reader ( $\mu \mathrm{Quant}$ Elisa reader, Bio-Tek, USA). The intra-assay (within the same day) and inter-assay (between days) variation was determined for bovine serum from the average of three replicates. The lowest measured concentration of nesfatin- 1 was $1.2 \mathrm{ng} /$ $\mathrm{mL}$, with intra- and inter-assay $\mathrm{CV}$ were $<10 \%$ and $<15 \%$, respectively. All samples were run in duplicate in the assay.

\section{STATISTICAL ANALYSIS}

The statistical significant differences between the control and BTB groups were determined for leptin, ghrelin, Nesfatin-1, total cholesterol, Triglyceride, LDL cholesterol VLDL cholesterol, HDL cholesterol, AST, ALT and CK by Student's t-test (SPSS 17.0); $P$ values $<0.05$ were considered statistically significant. The correlation between the nesfatin-1 concentration with leptin, ghrelin and other biochemical parameters were analysed using Pearson's rank correlation coefficient.

\section{RESULTS}

The mean age of the 15 cattle included in this study was $2.5 \pm 1.3$ years. The prevailing signs were enlarged lymph nodes, weakness, dermatitis, and mouth and skin ulcers.

In the present study, serum leptin, ghrelin, and nesfatin-1 concentrations, lipid profile parameters, and enzyme activities of the BTB group and healthy control are presented in table 2. And there were significant changes in lipid profile parameters and muscle enzymes activities in BTB group when compared with healthy controls.

In the study, the total cholesterol, triglyceride, LDL cholesterol and HDL cholesterol levels were found significantly lower in the BTB group than in the healthy controls. 
Table 2. Concentrations of serum nesfatin-1, leptin, ghrelin, lipid profile and musculer enzymes in BTB and healthy controls.

\begin{tabular}{lccc}
\hline Parameter & $\begin{array}{c}\text { Healthly Control } \\
(\mathrm{n}=15)\end{array}$ & $\begin{array}{c}\text { BTB } \\
(\mathrm{n}=15)\end{array}$ & $P$ value \\
\hline Leptin $(\mathrm{ng} / \mathrm{mL})$ & $3.85 \pm 0.35$ & $3.16 \pm 0.24 * * *$ & $P<0.001$ \\
Ghrelin $(\mathrm{pg} / \mathrm{mL})$ & $121 \pm 28$ & $138 \pm 36^{*}$ & $P<0.05$ \\
Nesfatin-1 (ng/mL) & $4.45 \pm 0.28$ & $5.22 \pm 0.37 * * *$ & $P<0.001$ \\
Total Cholesterol & $89.8 \pm 12.3$ & $64.9 \pm 10.7 * *$ & $P<0.01$ \\
Triglyceride & $71.4 \pm 11.15$ & $56.2 \pm 22.4 * * *$ & $P<0.001$ \\
LDL cholesterol & $47.1 \pm 5.4$ & $38.7 \pm 7.2 * *$ & $P<0.01$ \\
VLDL cholesterol & $7.6 \pm 2.6$ & $8.1 \pm 2.7$ & $P>0.05$ \\
HDL cholesterol & $61.5 \pm 5.36$ & $48.7 \pm 4.21 * *$ & $P<0.01$ \\
AST (IU/L) & $86.4 \pm 18$ & $115.6 \pm 26 * *$ & $P<0.001$ \\
ALT (IU/L) & $25.4 \pm 4.2$ & $48.6 \pm 5.1 * * *$ & $P<0.001$ \\
CK (IU/L) & $51.7 \pm 12.5$ & $91.3 \pm 19.8 * * *$ & $P<0.001$ \\
\hline
\end{tabular}

$*, * *, * * *$ differences are statistically significant among groups marked with different letters on the same line $(P<0.05, P<0.01, P<0.001$ respectively). Data are expressed as mean \pm standard error of the mean values AST; Aspartate aminotransferase, ALT; Alanine aminotransferase, CK; Creatinine kinase.

But no statistical difference was observed in VLDL levels between the groups. Serum AST, ALT, and CK activities were significantly higher $(P<0.001)$ in the BTB group when compared to the control group.

In this study we also found significant changes in appetite-related hormone concentrations of cattles with tuberculosis when compared with the healthy controls. Serum nesfatin- 1 concentrations were found significantly higher $(P<0.001)$ in BTB group than in the control group in the study (figure 1).

Whereas, leptin concentrations were lower $(P$ $<0.001$ ) than those of the controls (figure 2a). The mean concentration of ghrelin in cattle with tuberculosis was significantly higher $(P<0.05)$ than that of the control animals (figure 2b).

Positive weak correlations were observed between nesfatin- 1 and ghrelin concentrations ( $r=0.316$, figure $3 a)$, while there was a negative correlation between nesfatin-1

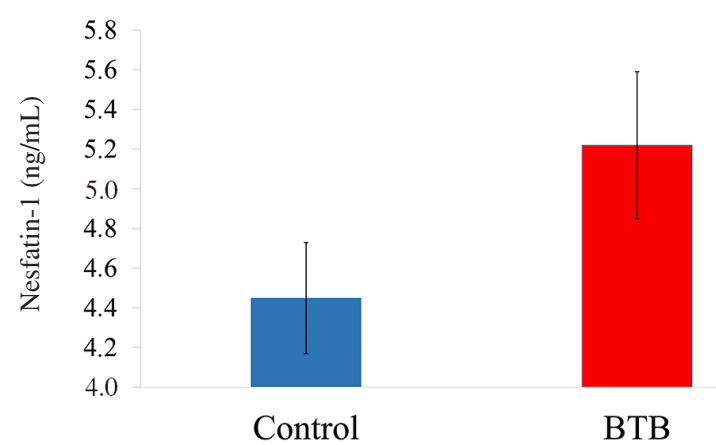

Figure 1. Changes in nesfatin-1 concentrations in BTB and healthy controls. There is a significant increase in BTB group $(P<0.001)$ when compared with the control group. BTB: bovine tuberculosis. and leptin ( $\mathrm{r}=-0.515$, figure $3 \mathrm{~b})$, triglyceride $(\mathrm{r}=-0.487)$, total cholesterol $(\mathrm{r}=-0.514)$, LDL cholesterol $(\mathrm{r}=-0.541)$. Likewise, positive correlations were found between nesfatin-1 and AST ( $\mathrm{r}=0.545)$, ALT $(\mathrm{r}=0.623)$, and CK $(\mathrm{r}=0.576)$ of cattle with TB.

\section{DISCUSSION}

Because of the serious economic implications and zoonotic concerns associated with Mycobacterium bovis infection, the eradication of Mycobacterium bovis infection is very important. Tuberculosis is known to decrease appetite in infected individuals, resulting in weight loss in domestic cattle (Chaddock 2002).

Previous research findings reveal that molecules like leptin and ghrelin, which are related to energy metabolism, are associated with human tuberculosis. Leptin plays a central role in the hormonal control of the energy balance. Several conflicting results have been reported for leptin levels in humans with TB: increased (Kim et al 2010, Zheng et al 2013), decreased (Keicho et al 2012) or not changed. In this study, serum leptin concentrations were significantly lower in the BTB group compared to the control group (figure 2a). Decreased leptin concentrations may be related with weight loss during the disease. Mycobacterium bovis infection may be associated with low serum concentrations of leptin. Serum levels of leptin decreased in BTB group and correlated negatively with nesfatin-1 concentrations (figure 3a).

We also evaluated serum ghrelin concentration which has functionally an opposed action of leptin because of its regulating role in appetite, food intake and energy metabolism. Serum ghrelin concentrations can change with acute as well as chronic eating problems (Ozturk et al 2013). Conflicting results were reported for ghrelin 
a)

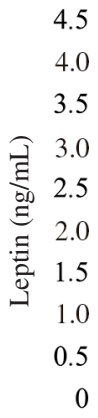

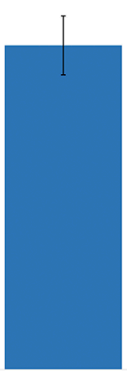

Control

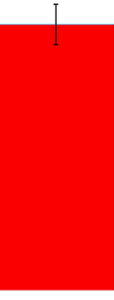

BTB b)

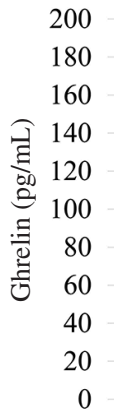

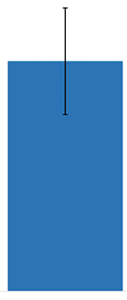

Control

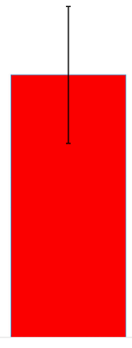

BTB

Figure 2. a) Changes in leptin concentrations in BTB and healthy controls. There is a significant decrease in the BTB group $(P<0.001)$ when compared with the control group. b) Ghrelin concentrations in both the BTB and healthy controls in the present study. There is a significant increase in BTB group $(P<0.05)$ when compared with the control group.

a)

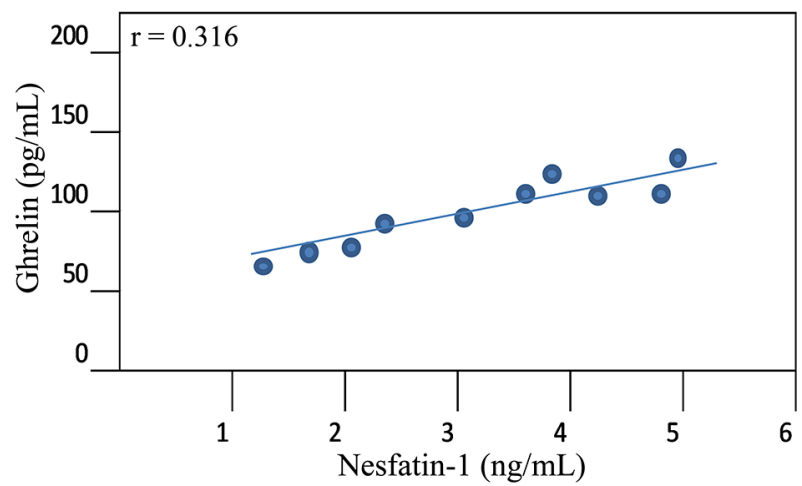

b)

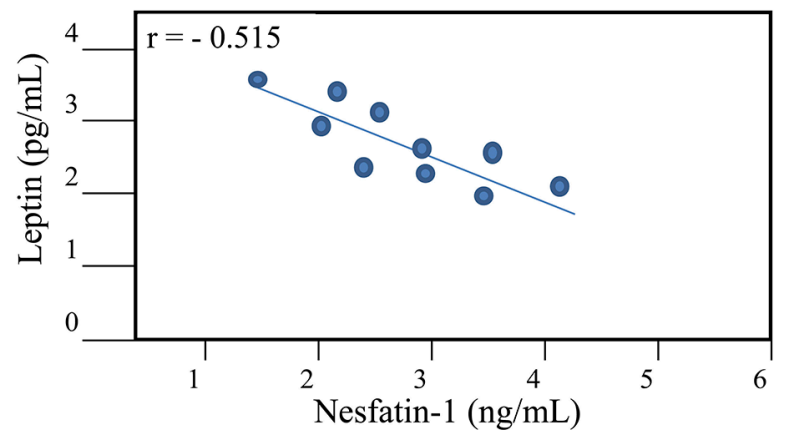

Figure 3. a) The correlation of Nesfatin- 1 and Ghrelin concentrations in bovine tuberculosis. Pearson's rank correlation coefficient was $\mathrm{r}=0.316, P<0.005$. b) The correlation of Nesfatin-1 and Leptin concentrations in bovine tuberculosis. Pearson's rank correlation coefficient was $r=-0.515, P<0.01$.

levels in tuberculosis and other pulmonary diseases such as chronic obstructive pulmonary disease (COPD), cystic fibrosis, and lung cancer (Kim et al 2010, Zheng et al 2013). In this study, serum ghrelin concentrations were significantly higher $(P<0.05)$ in the BTB group compared to the control group (figure $2 b$ ). The increase in serum ghrelin concentrations in the study may be linked to weight loss and anorexia in Mycobacterium bovis infection as a compensatory response.

As a novel anorexic peptide, studies about nesfatin-1 are limited. Nesfatin-1 is a peptide hormone that is produced in the brain of mammals and responsible for the production of body fat and the regulation of appetite. The study conducted has shown that excess nesfatin-1 in the brain leads to a loss of appetite, less frequent hunger, and a drop in body fat and weight (Steingel et al 2013). Abac1 et al (2013) determined that serum nesfatin-1 values in obese children are also decreased. In Mycobacterium bovis infection, signs such as loss of both appetite and weight are observed. In our study, nesfatin-1 levels were significantly higher in the Mycobacterium bovis infection group when compared to the healthy controls $(P<0.001$, figure 1$)$. Observed increases in nesfatin-1 levels may be related with weight loss and anorexia in Mycobacterium bovis infection as a result of the hormone role in inflammatory response.

Lipids are essential factors that determine our nutritional status and partipiciate in immune response. The significantly low concentrations of triglyceride, total cholesterol, LDL-cholesterol and HDL-cholesterol observed among tuberculosis patients in this study correlates with the findings of previous studies ${ }^{1}$ (Oyedeji et al 2013, Taparia et al 2015). Reduced concentrations of these lipid

1 Graveline D. 2016. Cholesterol and Tuberculosis. https://www. spacedoc.com/articles/ cholesterol-and-tuberculosis; date of access 20.04.2016. 
fractions could have resulted from tissue and cell damage and consequently, may lead to wasting away and weight loss, as are often observed in TB patients. The lower levels of the lipid fractions observed in TB patients when compared with the health controls could also be a result of the impaired rate of lipid production and enhanced rate of lipid catabolic rate associated with TB infection (Taparia et al 2015).

In the present study, serum muscular enzyme activities such as AST, ALT, and CK were also determined. It has long been recognised that ALT and AST are present in high concentrations in liver besides muscles, brain, etc. Nevertheless, these transaminases frequently are considered to be specific indicators of liver injury, several case reports demonstrate isolated hypertransaminasemia as an initial finding of muscle disease besides CK. Serum CK activity is greatest in striated muscle, heart tissue, and brain, and it is markedly elevated with breakdown of muscle. This may result from reduced muscle mass accompanying muscle wasting or cachectic states (Wright et al 2012). Significantly higher $(P<0.001)$ activities of AST, ALT, and CK were determined in the BTB group when compared to the control group in this study. Increased activities of these muscular enzymes can be related to muscle cell damage as a result of weight loss and anorexia in Mycobacterium bovis infection.

In conclusion, in addition to the other well-known appetite-related hormones leptin and ghrelin, in this study we determined the serum nesfatin- 1 concentrations in cattle with tuberculosis for the first time, in order to investigate their possible role in Mycobacterium bovis infection. The study reported increased concentrations of nesfatin- 1 in Mycobacterium bovis infection, but its exact role in the etiopathogenesis of Mycobacterium bovis infection requires further investigation.

\section{REFERENCES}

Abacı A, Catlı G, Anık A, Kume T, Bober E. 2013. The relation of serum nesfatin-1 level with metabolic and clinical parameters in obese and healthy children. Pediatr Diabetes 14, 189-195.

Anwar GM, Yamamah G, Ibrahim A, El-Lebedy D, Farid TM, et al. 2014. Nesfatin-1 in childhood and adolescent obesity and its association with food intake, body composition and insulin resistance. Regul Pept 188, 21-24.

Carstensen M, DonCarlos MW. 2011. Preventing the establishment of a wildlife disease reservoir: a case study of bovine tuberculosis in wild deer in Minnesota, USA. Vet Med Int Article ID 413240, https:// doi.org/10.4061/2011/413240.

Chaddock MH. 2002. Tuberculosis. In: Smith BP (ed). Large Animal Internal Medicine. $3^{\text {rd }}$ ed. Mosby Publications, London, UK, Pp 588-589.

Friedewald WT, Levy RI, Frederickson DS. 1972. Estimation of the concentration of low-density lipoprotein cholesterol in plasma, without use of the preparative ultracentrifuge. Clin Chem 18, 499-502.

Keicho N, Matsushita I, Tanaka T, Shimbo T, Hang NTL, et al. 2012. Circulating levels of adiponectin, leptin, fetuin-a and retinol-binding protein in patients with tuberculosis: markers of metabolism and inflammation. PLOS ONE 7, e38703.

Kessler EC, Gross JJ, Bruckmaier RM, Albrech C. 2014. Cholesterol metabolism, transport, and hepatic regulation in dairy cows during transition and early lactation. J. Dairy Sci 97, 5481-5490.

Kim JH, Lee CT, Yoon HI, Song J, Shin WY, et al. 2010. Relation of ghrelin, leptin and inflammatory markers to nutritional status in active pulmonary tuberculosis. Clin Nutr 29, 512-518.

Okafor CC, Grooms DL, Bruning-Fann CS, Averill JJ, Kaneene JB. 2011. Descriptive epidemiology of bovine tuberculosis in Michigan (1975-2010): Lessons Learned. Vet Med Int Article ID 874924, doi: $10.4061 / 2011 / 874924$.

Osorı JH, Suarez YJ, Perez JE. 2012. Validation of Friedewald's Formula for determining cattle lipid profile. Biosalud 11, 70-76.

Oyedeji SO, Adesina AA, Oke OT, Oguntuase NR, Esan A. 2013. Oxidative stress and lipid profile status in pulmonary tuberculosis patients in South Western Nigeria. Greener Journal of Medical Sciences 3, 228-232.

Ozturk AS, Guzel M, Askar TK, Aytekin I. 2013. Evaluation of the hormones responsible for the gastrointestinal motility in cattle with displacement of the abomasum; ghrelin, motilin and gastrin. Vet Rec 172, 636-640.

Steingel A, Mori M, Taché Y. 2013. The role of nesfatin-1 in the regulation of food intake and body weight: recent developments and future endeavors. Obes Rev 14, 859-870.

Şengül Ö, Dilbaz B, Halıcı Z, Ferah I, Çadırcı E, et al. 2014. Decreased serum nesfatin-1 levels in endometriosis. Eur J Obstet Gynecol Reprod Biol 177, 34-37.

Taparia P, Yadav D, Koolwal S, Mishra S. 2015. Study of lipid profile in pulmonary tuberculosis patients and relapse cases in relation with disease severity -A pilot study. IJSAR 2, 41-50.

Wang Y, Zhou X, Lin J, Yin F, Xu L, et al. 2011. Effects of Mycobacterium bovis onmonocyte-derived macrophages from bovine tuberculosis infection and healthy cattle. FEMS Microbiol Lett 321, 30-36.

Wright MA, Yang ML, Parsons JA, Westfall JM, Yee AS. 2012. Consider muscle disease in children with elevated transaminase. J Am Board Fam Med 25, 536-540.

Yurt S, Erman H, Korkmaz GG, Kosar AF, Uysal P, et al. 2013. The role of feed regulating peptides on weight loss in patients with pulmonary tuberculosis. Clin Biochem 46, 40-44.

Zheng Y, Ma A, Wang Q, Han X, Cai J, et al. 2013. Relation of leptin, ghrelin and inflammatory cytokines with body mass index in pulmonary tuberculosis patients with and without type 2 diabetes mellitus. PLOS ONE 8, e80122. 
